\title{
Online Social Support and Use of SNSs Among College Students: Relationship to Online and Offline Social Skills
}

\author{
YU, Shu-yin \\ Ming-Chuan University, Taoyuan, Taiwan
}

\begin{abstract}
The subjects of this study are college students aged between 18 to 26 years old from different majors. Investigated the use intensity and addiction of SNSs among college students, with variables of use behaviors and online social support are relate to their online social skills and offline social skills. Seven point Likert scale, descriptive statistics, One-way ANOVA and logistic regression were used to determine the correlations of different use intensities and levels of addiction. The results explored whether college students' online social skills, offline social skills, and online social support are correlated with use intensity and addiction. Long-term or high-frequency use of SNSs does not lead to equivalent social relationships on SNSs, yet addiction to SNSs can reflect the positive support and communication ability of college students in online interpersonal relationships.
\end{abstract}

Keywords: online social support, online social skills, offline social skills, use intensity, addiction

\section{Introduction}

\section{Background}

The development of digital media and technology has become an important influence, especially in the young generation (J. G. Gray \& N. D. Gray, 2006). Students are often trapped in the virtual world of social networking sites (SNSs). The benefits of SNSs, such as maintaining relationships with friends and family, make new friends, seeking advices or assistances from others, easing loneliness, and meeting the real-life social support functions, have replaced the actual needs of social life. Unlike the real world, the SNSs are overly idealized to meet the psychological needs, such as illusory sense of accomplishment, anonymity, avoidance of responsibility, addiction, interpersonal alienation in real life, and degradation of social skills. This phenomenon triggers addicted students to flee reality, become increasingly dependent on the Internet, and lose personal relationships, thus resulting in great harms on their physical and psychological well-being, as well as on the entire social economy.

\section{Objectives}

Online social support is a critical factor in understanding the influence of behaviors on SNSs. The influences on behaviors also include changes of real-world social skills. When social activities are fulfilled through online interactions, there are corresponding changes in real-world social behaviors. Therefore, the use behaviors of SNSs, online and face-to-face communication (offline) social skills have become important variables in research of online behaviors. This study aims to explore whether college students' use intensity and addiction are significantly related to online social support, online social skills, and offline social skills. It 
further validates whether the use intensity and addiction of SNSs can be used as the variables for predicting online social support, online social skills, and offline social skills.

\section{Literature}

\section{Social Networking Sites}

Social networking sites (SNSs), presented as a combination of all existing communication technologies, have become immensely popular (Bargh \& McKenna, 2004). Indications are that SNSs involve the consumption of digital media, and are primarily used for communication and interaction, rather than to acquire information. The trend of using SNSs is being accelerated by the pervasive use of smartphones. It has become a tool for bringing individuals with the same interests or social connections into contact (Ellison, Steinfield, \& Lampe, 2007), allowing them to sustain and strengthen their social relationships by exchanging information, announcing events through status updates, posing for photos or reading news feeds. The use of SNSs may result in stronger relationships than may be possible through face to face communication (Lenhart, Purcell, Smith, \& Zickuhr, 2010; Ross et al., 2009).

\section{Online Social Support}

Social networking sites provide a freer form of sharing and communication; thus, users would seek online support, in turn, change their actual behaviors due to the support from online groups. Walther (1996) pointed out that, compared to real-world support, online social support has more advantages, such as anonymity, immediacy, extensiveness, and fastness. Overall, SNSs not only have broadened the social scope of the users, but also increased their sources of social support.

Malecki and Demaray (2002) classified social support into four types, instrumental support, emotional support, social companionship support, and informational support. Instrumental support refers to providing services or materials to help others solve practical problems, including caretaking, monetary or material assistance. Emotional support involves showing concern for others so that they obtain a sense of security. Although emotional support is not as direct as instrumental support, it is one of the social supports frequently discussed in research. With emotional support, the recipients can evaluate their value and enhance their self-esteem through the concern of others in interpersonal communication; hence, it is also called esteem support. Social companionship support means that a person partakes in activities with others, seeks self-adaption, or a sense of belonging through companionship. Informational support indicates the substantial support of providing information, suggestions, or guidance to others. Based on the above, social support is a social relationship in interpersonal interaction, and different kinds of social support can offer individuals emotional and substantial assistance and satisfy personal social needs.

With low social support, college students often feel great social pressure, and often suffer negative emotions, such as depression and anxiety. Consequently, in the face of disputes, conflicts, or annoyances, they often lack confidence and assistance to solve their problems. As a result, they resort to the virtual world to temporarily free themselves from pressure. Compared with college students who have sufficient social support, most college students with low social support refuse to face reality and seek comfort online. Those with low social support have only a few friends in real life, they lack confidence, and are afraid of being turned down or receiving negative remarks. With little expectation of social support, they seldom have actual emotional communication with classmates and friends in an active manner; instead, they would choose to capitalize on the virtuality and anonymity of the Internet to create a new self to change their identity and status, 
hence, establish a confident role to communicate with strangers. To sum up, social support is relevant to use behaviors of SNSs.

\section{Online and Offline Social Skills}

Social skills refer to a person's ability to interact with others in social situations, and such ability is crucial for the establishment and maintenance of a relationship (Mallinckrodt, 2000). The theoretical foundation of social self-efficacy originated from the Self-efficacy Theory of Bandura (1977). Social self-efficacy advocates that individuals' psychological states are influenced by their cognition, and refer to their faith in obtaining success. This cognitive mechanism is called self-efficacy. An individual with a high level of self-efficacy is more confident in handling tasks, and is more willing to complete difficult tasks, has more persistence in solving problems, and seldom complains about failure.

Influenced by online interactions, social skill has become an important variable in studies of online behaviors. Misra et al. (2014) suggested that, communication through networks or interactive devices is a sign of a serious lack of emotion and sympathy. Communications through online communities create significant negative effects on interpersonal intimacy, relationships, and dialogues (Przybylski \& Weinstein, 2012). Communication through interactive devices affects an individual's interpersonal relationships and face-to-face exchange with others in reality (Campbell \& Kwak, 2011). According to Brignall and van Valey (2005), SNSs have become an essential social tool for youngsters in daily life. In addition to weakening their face-to-face communication ability, it affects the development of their social skills and hinders their self-expression.

\section{Method}

\section{Design}

Social support is an indicator of a person's social psychology, which is important but difficult to observe. Compared with traditional media, SNSs have changed the form of interpersonal communication. Investigation on the use behaviors of SNSs could provide further understanding to individuals' social relationships, thus help to predict the psychological traits certain groups. Therefore, this study aims to explore whether college students' use intensity and addiction of SNSs are correlated with their online social support and social skills. Moreover, it attempts to determine whether the use intensity and addiction can be used as variables to predict their online social support and social skills.

The questionnaire used in this study adopted a 7-point Likert scale. The results were analyzed using SPSS for the validation of the research hypotheses. The significance and correlation of the research were validated by t-test, ANOVA, and regression analysis. Part I of the questionnaire collects the basic information of the respondents, such as gender, age, study field, and academic achievement (GPA). Part II concerns the use behaviors and addiction of SNSs. Part III is the self-evaluation of online social support and social skills, including online and offline social skill. The reliability and validity of the items were tested. Based on the results, the items were modified for the formal survey.

\section{Hypotheses}

According to the research purposes, the following hypotheses were developed:

H1: The use intensity, level of addiction, online social support, online and offline social skills of the subjects have significant differences.

H2: Use intensity and addiction have correlations with online social support and social skills. 
H3: For subjects with different use intensities and levels of addiction, there are correlations among their online social support, online and offline social skills.

H4: Use intensity and addiction can be used as variables to predict college students' online social support, online and offline social skills.

\section{Measurement}

Use intensity. The use behavior of SNSs of college students were measured with two independent variables, namely use intensity and level of addiction. Use intensity was calculated by the total scores of usage time, usage frequency, exposure period, and number of friends. The scores were given based on the intensity, i.e., 6 points for "all the time", 5 points for "many times in a day", and so forth. The total score ranges from 4 points to 23 points. Those with a score ranged from 18 points to 23 points are heavy users; those from 11 points to 17 points are moderate users; those from 4 points to 10 points are light users. For example, an individual who uses SNSs many times a day ( 5 points) for 3 to 5 hours a day ( 3 points), has 451 to 550 friends (6 points), and has been using SNSs for over 9 years ( 6 points), has a total score of 20 points, which indicates a heavy user. An individual who uses SNSs many times a day (5 points) for 1 to 3 hours a day (2 points), has 251 to 350 friends (4 points), and has been using SNSs for 3-4 years (3 points), has a total score of 14 points, which indicates a moderate user. An individual who uses SNSs only once a day (4 points) for 1 to 3 hours a day (2 points), has less than 50 friends (1 point), and has been using SNSs for 3-4 years ( 3 points), has a total score of 10 points, which indicates a light user.

Addiction. The addiction scale used in this study was modified from the addiction scale developed by Drago (2015). The items were modified regarding the overuse and addiction of mobile networks. The scale contains two reverse items, which are "I think that the SNS tools have a negative effect on my offline social skills" and "I have noticed that when I am using SNSs, the quality of my conversion in real world is affected". They were used as the indicators of the scale, and for discrimination purpose. The $t$ values of the reverse items after the critical ratio (CR) value analysis showed significant differences $(t=-2.753, \mathrm{p}=0.006<0.05 ; t=10.415$, $p=0.000<0.05$ ). This suggests that there is no acquiescent bias and the scale has discrimination.

Online social support. This study focuses on the social support in the interactions of SNSs, namely, the perceived care and adaptation through the direct or indirect assistance or support received from others through interaction on SNSs. This study modified the Interpersonal Support Evaluation List (ISEL-12) developed by Cohen and Wills (1985) and Malecki and Demaray (2002), in order to measure the social support received by the subjects on SNSs. The measuring variables included emotional support, information support, instrumental support, and social companionship.

Online and offline social skills. Individuals with good social skills can develop effective interpersonal social support, and are more likely to establish friendships in life (Taylor, 2003). This study assumes that, college students with high use intensity or addiction would receive more online social support, thus enhancing their online social skills and affect their offline social skills. This study thus adopted the Social Self-Efficacy Scale developed by Sherer and Madux (1982) to measure the ability and faith in communication with others. The scale contains two parts, online social skills and offline social skills. The measurement scope includes initiative, ability, persistence, addiction, degree of need, and assimilation of groups.

\section{Subjects}

The subjects of this study were 222 undergraduate and graduate students, who are aged 18 to 26 , and have 
used SNSs. Among the subjects, $59.0 \%$ are male and $41.0 \%$ are female; $8.1 \%$ are freshmen, $15.3 \%$ are sophomores, $18.5 \%$ are juniors, $50.9 \%$ are seniors, and $7.2 \%$ are graduate students. Regarding their grade point average, $33.8 \%$ have a score of $71-80$ points, and $43.7 \%$ have a score of $81-90$ points. The details are shown in Table 1.

Table 1

Basic Information of the Subjects and Their Use Behavior of SNSS

\begin{tabular}{|c|c|c|c|c|c|}
\hline Gender & $N$ & $\%$ & Study field & $N$ & $\%$ \\
\hline female & 131 & 59.0 & Business and Management & 48 & 21.6 \\
\hline male & 91 & 41.0 & Information & 22 & 9.9 \\
\hline Grade & & & Communication & 4 & 1.8 \\
\hline freshmen & 18 & 8.1 & Law & 3 & 1.4 \\
\hline sophomore & 34 & 15.3 & Hospitality and Tourism & 9 & 4.1 \\
\hline junior & 41 & 18.5 & Education and Applied Languages & 31 & 14.0 \\
\hline senior & 113 & 50.9 & Arts and Design & 58 & 26.1 \\
\hline graduate & 16 & 7.2 & Medical and Health Science & 16 & 7.2 \\
\hline GPA & & & Science & 17 & 7.7 \\
\hline under 60 & 1 & 0.5 & Other & 14 & 6.3 \\
\hline $61-70$ & 36 & 16.2 & Usage frequency, & & \\
\hline $71-80$ & 75 & 33.8 & followed by all the time & 63 & 28.4 \\
\hline $81-90$ & 97 & 43.7 & many times a day use & 148 & 66.7 \\
\hline $91-100$ & 13 & 5.9 & once a day use & 3 & 1.4 \\
\hline Exposure period & & & 1-2 days use & 3 & 1.4 \\
\hline under a year & 1 & 0.5 & 3-4 days use & 0 & 0 \\
\hline $1-2$ years & 1 & 0.5 & occasional use & 5 & 2.3 \\
\hline $3-4$ years & 35 & 15.8 & Number of friends & & \\
\hline $5-6$ years & 69 & 31.1 & under 50 friends & 7 & 3.2 \\
\hline $7-8$ years & 65 & 29.3 & 51 to 150 friends & 31 & 14.0 \\
\hline above 9 years & 51 & 23.0 & 151 to 250 friends & 37 & 16.7 \\
\hline Usage time & & & 251 to 350 friends & 47 & 21.2 \\
\hline under 60 mins & 23 & 10.4 & 351 to 450 friends & 27 & 12.2 \\
\hline 1-3 hrs a day & 102 & 45.9 & 451 to 550 friends & 17 & 7.7 \\
\hline $3-5$ hrs a day & 56 & 25.2 & over 551 friends & 56 & 25.2 \\
\hline above 5 hrs & 41 & 18.5 & & & \\
\hline
\end{tabular}

Regarding their exposure to SNSs, 31.1\% have used SNSs for 5-6 years, 29.3\% have used SNSs for 7-8 years, and $23.0 \%$ have used SNSs for over 9 years. As for the usage frequency, most subjects use SNSs many times a day (66.7\%), followed by all the time (28.4\%). In terms of usage time, $45.9 \%$ use SNSs for 1-3 hours a day. The number of friends is dispersed, $25.2 \%$ have over 551 friends and $21.2 \%$ have 251 to 350 friends. According to the statistics, college students have a long exposure period to SNSs, have frequent usage and a large number of friends, and use SNSs for 1-3 hours a day. This indicates that most college students are moderate to heavy users.

\section{Results}

\section{Analysis}

The results of the reliability test suggest that after deleting the items in each scale with correlation coefficients $<0.4$ and factor loading $<0.5$ according to the homogeneity test, all scales have high homogeneity. 
The Cronbach's $\alpha$ of addiction is 0.816 ; that of online social support is 0.819 ; that of emotional support is 0.942 ; that of informational support is 0.926 ; that of instrumental support is 0.932 ; that of social companionship support is 0.948 ; that of online social skills is 0.910 ; that of offline social skills is 0.954 . This indicates that the measurement indicators have high consistency (see Table 2). In other words, the scales of addiction, social support (including the four dimensions), and social skills have high reliability.

The results of differential test on use intensity (4-23 points) and addiction show $t=66.311$ and $10.729, p=$ $0.000<0.05$, respectively, suggesting that there is a significant difference in the use intensity and addiction of SNSs among college students. Except for social companionship support, the overall social support and other three dimensions are at a significant level, which indicates that there are significant differences among online social support, emotional support, informational support, and instrumental support for college students. In terms of social skills, only offline social skills reach a significant level $(t=18.184, p=0.000<0.05)$, which shows that there is no significant difference in online social skills among college students, but there is a difference in offline social skills (Table 2).

Table 2

Results of Differential Test on Variables

\begin{tabular}{lclllllll}
\hline & Mean & SD & $\alpha$ & $T$ & Sig & $F$ & $P$ & Total variance \\
\hline Use intensity (4-23) & 16.73 & 2.86 & & 66.311 & $0.000^{* *}$ & & & \\
Addiction & 4.77 & 1.07 & 0.816 & 10.729 & $0.000^{* *}$ & 80.532 & $0.000^{* *}$ & 64.198 \\
Social support & 4.41 & 1.15 & 0.819 & 5.336 & $0.000^{* *}$ & 7.684 & $0.000^{* *}$ & 19.742 \\
Emotional & 4.56 & 1.21 & 0.942 & 6.852 & $0.000^{* *}$ & 19.742 & $0.000^{* *}$ & 74.403 \\
Informational & 4.62 & 1.15 & 0.926 & 7.997 & $0.000^{* *}$ & 64.920 & $0.000^{* *}$ & 70.026 \\
Instrumental & 4.30 & 1.22 & 0.932 & $3 \mathrm{ss} .665$ & $0.000^{* *}$ & 25.223 & $0.000^{* *}$ & 71.339 \\
Companionship & 4.17 & 1.33 & 0.948 & 1.892 & 0.060 & 22.604 & $0.000^{* *}$ & 76.595 \\
Online social skill & 4.06 & 1.09 & 0.910 & 0.781 & 0.435 & 28.793 & $0.000^{* *}$ & 70.710 \\
Offline social skill & 5.27 & 1.04 & 954 & 18.184 & $0.000^{* *}$ & 37.392 & $0.000^{* *}$ & 70.518 \\
\hline
\end{tabular}

Note. ${ }^{*} P<0.05,{ }^{* *} P<0.01$.

Most subjects have high social support and good social skills. Their offline social skills score $(M=5.275)$ is significantly higher than that of other variables, suggesting that the subjects have good offline social skills (see Table 3).

The results of Levene's test on different levels of use intensity and addiction do not reach a level of significance, suggesting that the dispersion of the subjects has no significant difference. The overall test results show that for subjects of different use intensities, their social support is $(F=3.034, p=0.05)$, emotional support is $(F=3.180, p=0.044<0.05)$, instrumental support is $(F=3.493, p=0.032<0.05)$, and offline social skills is $(F=3.039, p=0.05)$. This suggests that those variables have differences due to use intensity. Among the subjects, the four dimensions of social support and online social skills of moderate users are higher than those of heavy users. It can be inferred that, heavy users may not use SNSs due to better social relations or social skills on SNSs; on the contrary, moderate users have better interactions and positive relationships on SNSs. All variables of the subjects reach the level of significance, regardless of their addiction level. This indicates that there are differences in online social support, online social skills, and offline social skills for subjects with different addiction levels. 
Table 3

One-way ANOVA of the Subjects With Different Levels of Use Intensity and Addiction

\begin{tabular}{|c|c|c|c|c|c|c|c|c|}
\hline $\mathrm{M} / \mathrm{Sd}$ & $N$ & $\begin{array}{l}\text { Social } \\
\text { support }\end{array}$ & Emotional & Informational & Instrumental & Companionship & $\begin{array}{l}\text { Online } \\
\text { social skill }\end{array}$ & $\begin{array}{l}\text { Offline } \\
\text { social skills }\end{array}$ \\
\hline \multirow{2}{*}{ Total } & \multirow{2}{*}{222} & 4.411 & 4.555 & 4.617 & 4.301 & 4.169 & 4.057 & 5.275 \\
\hline & & 1.147 & 1.208 & 1.150 & 1.224 & 1.333 & 1.086 & 1.045 \\
\hline \multirow{2}{*}{ Light users } & \multirow{2}{*}{31} & 3.969 & 4.078 & 4.207 & 3.788 & 3.802 & 3.753 & 4.857 \\
\hline & & 1.192 & 1.135 & 1.177 & 1.245 & 1.370 & 1.013 & 1.031 \\
\hline \multirow{2}{*}{ Moderate users } & \multirow{2}{*}{128} & 4.528 & 4.681 & 4.718 & 4.429 & 4.285 & 4.147 & 5.319 \\
\hline & & 1.135 & 1.170 & 1.149 & 1.236 & 1.323 & 1.085 & 1.035 \\
\hline \multirow{2}{*}{ Heavy users } & \multirow{2}{*}{63} & 4.390 & 4.535 & 4.615 & 4.295 & 4.116 & 4.023 & 5.391 \\
\hline & & 1.111 & 1.275 & 1.111 & 1.141 & 1.321 & 1.109 & 1.036 \\
\hline \multirow{2}{*}{\multicolumn{2}{|c|}{$\begin{array}{l}\text { Levene Statistics } \\
\text { Significance }\end{array}$}} & 0.020 & 0.977 & 0.047 & 0.067 & 0.001 & 0.225 & 0.226 \\
\hline & & $(0.980)$ & $(0.378)$ & $(0.954)$ & $(0.935)$ & $(0.999)$ & $(0.799)$ & $(0.798)$ \\
\hline \multirow{2}{*}{\multicolumn{2}{|c|}{$\begin{array}{l}\text { F test } \\
\text { Significance }\end{array}$}} & $F=3.034$ & $F=3.180$ & $F=2.491$ & $F=3.493$ & $F=1.719$ & $F=1.696$ & $F=3.039$ \\
\hline & & $\left(0.050^{*}\right)$ & $\left(0.044^{*}\right)$ & $(0.085)$ & $\left(0.032^{*}\right)$ & $(0.182)$ & $(0.186)$ & $\left(0.050^{*}\right)$ \\
\hline \multirow{2}{*}{$\begin{array}{l}\text { Light addiction } \\
\text { user }\end{array}$} & \multirow{2}{*}{19} & 3.461 & 3.617 & 3.669 & 3.218 & 3.338 & 3.477 & 4.362 \\
\hline & & 0.865 & 1.022 & 1.007 & 0.881 & 1.003 & 1.085 & 1.047 \\
\hline \multirow{2}{*}{$\begin{array}{l}\text { Moderate } \\
\text { addiction user }\end{array}$} & \multirow{2}{*}{117} & 4.134 & 4.209 & 4.358 & 4.076 & 3.893 & 3.740 & 5.212 \\
\hline & & 0.988 & 1.011 & 0.990 & 1.060 & 1.184 & 0.982 & 1.007 \\
\hline \multirow{2}{*}{$\begin{array}{l}\text { Heavy addiction } \\
\text { user }\end{array}$} & \multirow{4}{*}{86} & 4.998 & 5.234 & 5.179 & 4.847 & 4.729 & 4.616 & 5.563 \\
\hline & & 1.129 & 1.160 & 1.127 & 1.252 & 1.385 & 0.985 & 0.972 \\
\hline \multirow{2}{*}{$\begin{array}{l}\text { Levene Statistics } \\
\text { Significance }\end{array}$} & & 1.284 & 1.379 & 0.781 & 2.212 & 1.431 & 0.250 & 0.184 \\
\hline & & $(0.279)$ & $(0.254)$ & $(0.459)$ & $(0.112)$ & $(0.241)$ & $(0.779)$ & $(0.832)$ \\
\hline F test & & $\mathrm{F}=25.982$ & $F=30.627$ & $F=23.787$ & $F=21.263$ & $F=15.626$ & $F=22.879$ & $F=11.781$ \\
\hline Significance & & $\left(0.000^{* *}\right)$ & $\left(0.000^{* *}\right)$ & $\left(0.000^{* *}\right)$ & $\left(0.000^{* *}\right)$ & $\left(0.000^{* *}\right)$ & $\left(0.000^{* *}\right)$ & $\left(0.000^{* *}\right)$ \\
\hline
\end{tabular}

Notes. ${ }^{*} P<0.05,{ }^{* *} P<0.01$.

Table 4

Results of Simple Regression Analysis on Use Intensity and Addiction in Relation to the Four Dimensions of Social Support, and Online and Offline Social Skills

\begin{tabular}{|c|c|c|c|c|c|c|c|}
\hline & Variables & $\mathrm{R}^{2}$ & Beta & $\mathrm{T}$ test & Sig & $\mathrm{F}$ test & Sig \\
\hline \multirow{2}{*}{ Social support } & Intensity & \multirow[t]{2}{*}{0.188} & 0.030 & 0.477 & 0.634 & \multirow[t]{2}{*}{25.381} & \multirow[t]{2}{*}{$0.000^{* *}$} \\
\hline & Addiction & & 0.426 & 6.833 & $0.000^{* *}$ & & \\
\hline \multirow{2}{*}{ Emotional } & Intensity & \multirow[t]{2}{*}{0.216} & 0.030 & 0.486 & 0.627 & \multirow[t]{2}{*}{30.196} & \multirow[t]{2}{*}{$0.000^{* *}$} \\
\hline & Addiction & & 0.458 & 7.463 & $0.000^{* *}$ & & \\
\hline \multirow{2}{*}{ Informational } & Intensity & \multirow[t]{2}{*}{0.175} & 0.000 & -0.004 & 0.997 & \multirow[t]{2}{*}{23.229} & \multirow[t]{2}{*}{$0.000^{* *}$} \\
\hline & Addiction & & 0.418 & 6.652 & $0.000^{* *}$ & & \\
\hline \multirow{2}{*}{ Instrumental } & Intensity & \multirow[t]{2}{*}{0.162} & 0.057 & 0.898 & 0.370 & \multirow[t]{2}{*}{21.146} & \multirow[t]{2}{*}{$0.000^{* *}$} \\
\hline & Addiction & & 0.386 & 6.089 & $0.000^{* *}$ & & \\
\hline \multirow{2}{*}{ Companionship } & Intensity & \multirow[t]{2}{*}{0.118} & 0.023 & 0.358 & 0.721 & \multirow[t]{2}{*}{14.608} & \multirow[t]{2}{*}{$0.000^{* *}$} \\
\hline & Addiction & & 0.337 & 5.185 & $0.000^{* *}$ & & \\
\hline \multirow{2}{*}{ Online social skill } & Intensity & \multirow[t]{2}{*}{0.197} & 0.006 & 0.089 & 0.929 & \multirow[t]{2}{*}{26.914} & \multirow[t]{2}{*}{$0.000^{* *}$} \\
\hline & Addiction & & 0.443 & 7.140 & $0.000^{* *}$ & & \\
\hline \multirow{2}{*}{ offline social skill } & Intensity & \multirow[t]{2}{*}{0.100} & 0.023 & 0.354 & 0.724 & \multirow[t]{2}{*}{12.180} & \multirow[t]{2}{*}{$0.000^{* *}$} \\
\hline & Addiction & & 0.310 & 4.727 & $0.000^{* *}$ & & \\
\hline
\end{tabular}

Notes. ${ }^{*} P<0.05,{ }^{* *} P<0.01$. 
According to the results of simple regression analysis (see Table 4) on use intensity and addiction in relation to the four dimensions of social support, online social skills and offline social skills, the overall social support is $R^{2}=0.188, F_{(2,219)}=25.381, P=0.000<0.05$; emotional support is $R^{2}=0.216, F_{(2,219)}=30.196, P=$ $0.000<0.05$; informational support is $R^{2}=0.175, F_{(2,219)}=23.229, P=0.000<0.05$; instrumental support is $R^{2}=0.162, F_{(2,219)}=21.146, P=0.000<0.05$; companionship support is $R^{2}=0.118, F_{(2,219)}=14.608, P=$ $0.000<0.05$; online social skills is $R^{2}=0.197, F_{(2,219)}=26.914, P=0.000<0.05$; offline social skills is $R^{2}=$ $0.100, F_{(2,219)}=12.180, P=0.000<0.05$. The results show that the explanatory power has statistical significance. Among all variables, only addiction can be effectively used for prediction. The predicative and explanatory power of social support is $18.8 \%$ and its Beta coefficient is $0.426(t=6.833, p=0.000<0.05)$, suggesting that those with stronger addiction have greater social support, emotional support, informational support, instrumental support, and companionship support.

The predicative and explanatory power of online social skills is $19.7 \%$, and its Beta coefficient is 0.443 ( $t$ $=7.140, p=0.000<0.05)$, indicating that stronger addiction leads to better online social skills. However, the predicative and explanatory power of offline social skills is $10.0 \%$, and its Beta coefficient is $0.310(t=4.727$, $p=0.000<0.05$ ), suggesting that those with stronger addiction have better offline social skills.

\section{Discussion}

The results of the hypotheses validation are shown in Table 5 .

There are significant differences among use intensity, addiction, emotional support, informational support, instrumental support, and offline social skills. Addiction has a positive correlation with social support and social skills. Strong addiction indicates greater social support and better social skills. Hence, it is valid to use addiction as the variable to predict the social support and social skills of college students, and has positive relations with the two. Moreover, it can be used as a variable to predict the four dimensions of social support.

Table 5

Results of Hypotheses Validation

\begin{tabular}{|l|l|l|}
\hline Hypothesis & Result & Description \\
\hline $\begin{array}{l}\text { H1: The use intensity, level of addiction, online social support, online } \\
\text { and offline social skills of the subjects have significant differences. }\end{array}$ & $\begin{array}{l}\text { Partially } \\
\text { supported }\end{array}$ & $\begin{array}{l}\text { Online social skill and companionship } \\
\text { support are below the significant level }\end{array}$ \\
\hline $\begin{array}{l}\text { H2: Use intensity and addiction have correlations with online social } \\
\text { support and social skills. }\end{array}$ & $\begin{array}{l}\text { Partially } \\
\text { supported }\end{array}$ & $\begin{array}{l}\text { Use intensity and some variables are } \\
\text { below the significant level }\end{array}$ \\
\hline $\begin{array}{l}\text { H3: For subjects with different use intensities and levels of addiction, } \\
\text { there are correlations among their online social support, online and } \\
\text { offline social skills. }\end{array}$ & $\begin{array}{l}\text { Partially } \\
\text { supported }\end{array}$ & $\begin{array}{l}\text { Use intensity and some variables are } \\
\text { below the significant level } \\
\text { Addiction all reach the significant level }\end{array}$ \\
\hline $\begin{array}{l}\text { H4: Use intensity and addiction can be used as variables to predict } \\
\text { college students' online social support, online and offline social skills. }\end{array}$ & $\begin{array}{l}\text { Partially } \\
\text { supported }\end{array}$ & $\begin{array}{l}\text { Addiction can effectively predict all } \\
\text { variables }\end{array}$ \\
\hline
\end{tabular}

Figure 1 is plotted with the means of different use intensities. As seen, college students have good offline social skills. Moderate users have greater social support (all four dimensions) and better online social skills than heavy users do; but they have equivalent offline social skills. Figure 2 shows that there is a significant difference among subjects of different levels of addiction. Heavy addiction users have higher means and better online social skills, while moderate and light addiction users have average or below average online social skills. 


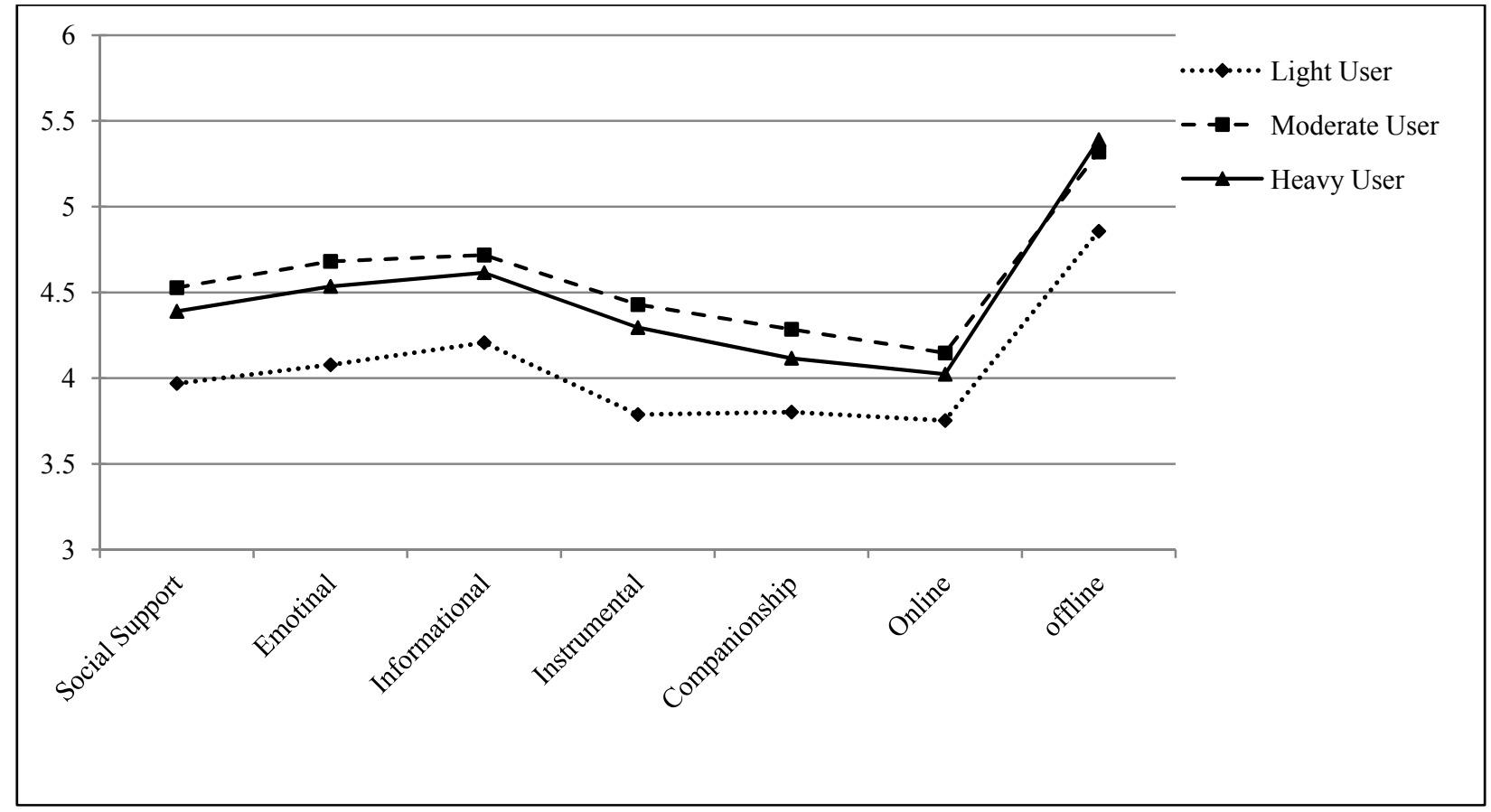

Figure 1. Line chart of the means of different use intensities.

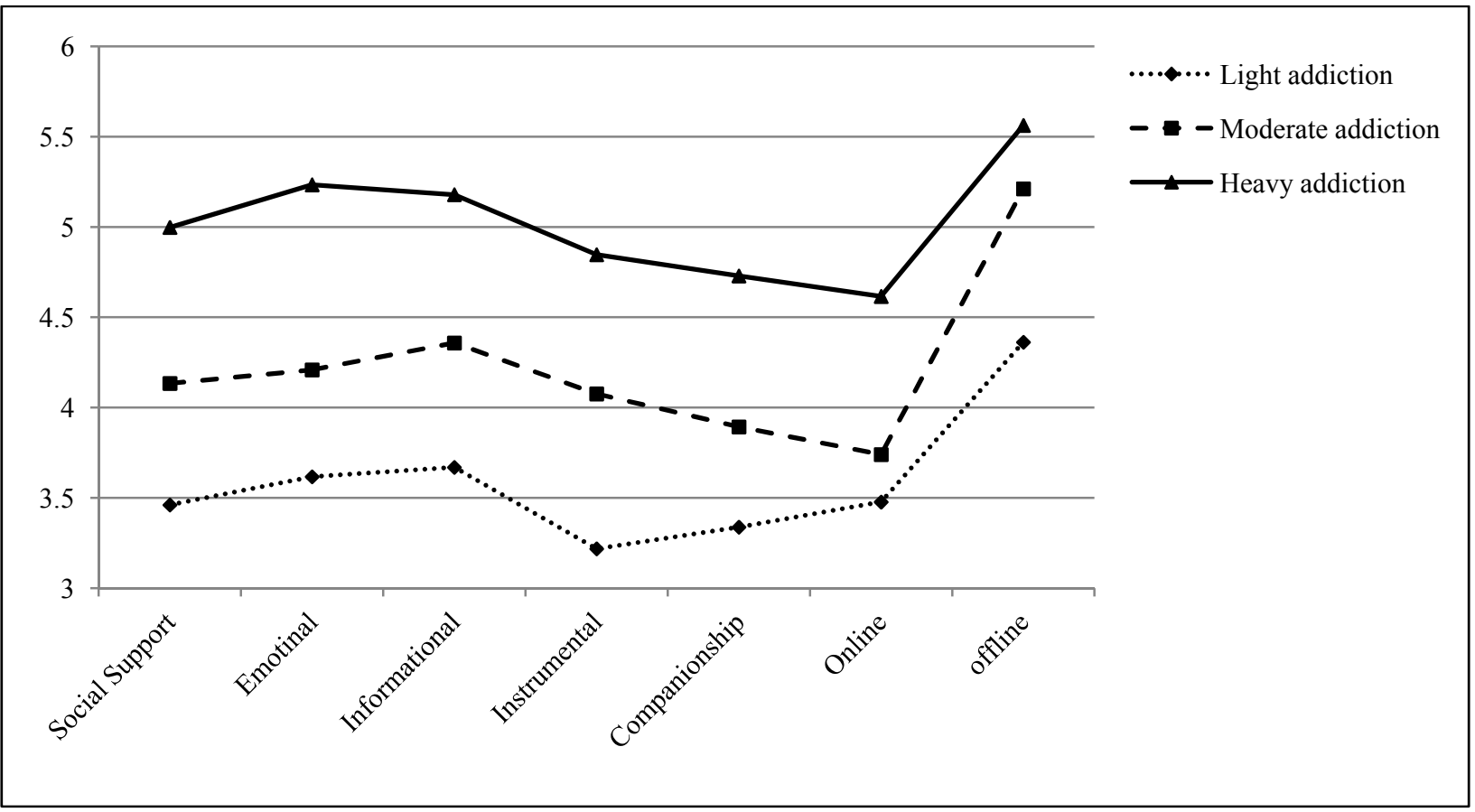

Figure 2. Line chart of the means of different levels of addiction.

\section{Conclusion}

Most college students are moderate and heavy users of SNSs. High-frequency or long-term use of SNSs has become the common lifestyle of students today. From SNS, they exchange their emotions, acquire information, and even feel a sense of contentment brought by companionship and belonging. Although they 
spend much time on the Internet and receive great online social support, their offline social skills remain better than online social skills. They feel comfortable communicating with friends in real life, and have close relationships with them. However, good offline social skills may not lead to good online social skills on SNSs. Those with good online social skills receive greater online social support.

Compared with heavy users, moderate users have better online and offline social skills. This means that usage time does not necessarily lead to the satisfaction of relationships and needs. In other words, although many college students visit SNSs many times a day, or even all the time, they fail to obtain equivalent emotional satisfaction or develop relationships.

Addiction of SNSs can be used as the most representative reference indicator on college students' use of SNSs. The results show that, long-term or high-frequency use of SNSs does not lead to equivalent social relationships on SNSs, yet addiction to SNSs can reflect the positive support and communication ability of college students in online interpersonal relationships.

\section{References}

Bandura, A. (1977). Self-efficacy: Toward a unifying theory of behavioral change. Psychological Review, 84(2), 191-215.

Brignall, T. W., \& van Valey, T. (2005). The impact of Internet communications on social interaction. Sociological Spectrum, 25, 335-348.

Campbell, S. W., \& Kwak, N. (2011). Mobile communication and civil society: Linking patterns and places of use to engagement with others in public. Human Communication Research, 37, 207-222.

Cohen, S., \& Will, T. A. (1985). Stress, social support, and the buffering hypothesis, Psychol. Bulletin, 98(2), 310-357.

Drago, E. (2015). The effect of technology on face-to-face communication. The Elon Journal of Undergraduate Research in Communications, 6(1), 13-19.

Ellison, N. B., Steinfield, C., \& Lampe, C. (2007). The benefits of Facebook “friends" social capital and college students' use of online social network sites. Journal of Computer-Mediated Communication, 12(4), 1143-1168.

Gray, J. G., \& Gray, N. D. (2006). The Web of Internet dependency: Search results for the mental health professional. International Journal of Mental Health and Addiction, 4, 307-318.

Lehman, A. (2005). JmpFor basic univariate \& multivariate statistics: A step-by-step guide. Cary, NC: SAS Press.

Lenhart, A., Purcell, L., Smith, A., \& Zickuhr, K. (2010). Social media and young adults. Retrieved from http://www.pewinternet.org/Reports/2010/Social-Media-and-Young-Adults.aspx

Malecki, C. K., \& Demaray, M. K. (2006). Social support as a buffer in the relationship between socioeconomic status and academic performance. School Psychology Quarterly, 21, 375-395.

Mallinckrodt, B. (2000). Attachment, social competencies, social support and interpersonal process in psychotherapy. Psychotherapy Research, 10, 239-266.

Misra, S., Cheng, L., Genevie, J., \& Yuan, M. (2014). The iphone effect: The quality of in-person social interactions in the presence of mobile device. Environment \& Behavior (pp. 1-24).

Przybylski, A. K., \& Weinstein, N. (2012). Can you connect with me now? How the presence of mobile communication technology influences face-to-face conversation quality. Journal of Social and Personal Relationships, 1(1), 1-10.

Ross, C., Orr, E. S., Mia Sisic, B. A., Arseneault, J. M., Simmering, M. G., \& Orr, R. R. (2009). Personality and motivations associated with facebook use. Computers in Human Behavior, 25(2), 578-586.

Sherer, M., \& Madux, J. E. (1982). The self-efficacy scale: Construction and validation. Psychological Report, 51, 663-671.

Taylor, T. L. (2003). Power gamers just want to have fun: Instrumental play in a MMOG. Retrieved from http://www.itu.dk/people/tltaylor/papers/Taylor-Powergamers.pdf

Walther, J. B. (1996). Computer-mediated communication: Impersonal, interpersonal, and hyper-personal interaction. Communication Research, 23, 3-43.

Weber, L. (2007). Marketing to the social web: How digital customers communities build your business. Hoboken, NJ: Wiley. 